\title{
Tree thinking cannot taken for granted: challenges for teaching phylogenetics
}

\author{
Hanno Sandvik
}

Received: 25 September 2007/Accepted: 15 January 2008/Published online: 5 February 2008

(C) The Author(s) 2008

\begin{abstract}
Tree thinking is an integral part of modern evolutionary biology, and a necessary precondition for phylogenetics and comparative analyses. Tree thinking has during the 20th century largely replaced group thinking, developmental thinking and anthropocentricism in biology. Unfortunately, however, this does not imply that tree thinking can be taken for granted. The findings reported here indicate that tree thinking is very much an acquired ability which needs extensive training. I tested a sample of undergraduate and graduate students of biology by means of questionnaires. Not a single student was able to correctly interpret a simple tree drawing. Several other findings demonstrate that tree thinking is virtually absent in students unless they are explicitly taught how to read evolutionary trees. Possible causes and implications of this mental bias are discussed. It seems that biological textbooks can be an important source of confusion for students. While group and developmental thinking have disappeared from most textual representations of evolution, they have survived in the evolutionary tree drawings of many textbooks. It is quite common for students to encounter anthropocentric trees and even trees containing stem groups and paraphyla. While these biases originate from the unconscious
\end{abstract}

\section{H. Sandvik}

Institutt for biologi, Universitetet i Troms $\varnothing$,

9037 Troms $\varnothing$, Norway

H. Sandvik

Avdeling for fiskeri- og naturfag, Høgskolen i Bodø,

8049 Bod $\varnothing$, Norway

\section{H. Sandvik ( $\square)$}

Centre for Conservation Biology, Institutt for biologi, Norges teknisk-naturvitenskapelige universitet (NTNU), 7491 Trondheim, Norway

e-mail: hanno@evol.no philosophical assumptions made by authors, the findings suggest that presenting unbiased evolutionary trees in biological publications is not merely a philosophical virtue but has also clear practical implications.

Keywords Biological education - Cladogram . Essentialism · Evolutionary tree · Group thinking · Stem group

\section{Introduction}

Modern evolutionary biology relies on population thinking and tree thinking (O'Hara 1997). Both ways of thinking have replaced earlier philosophies that turned out to be incompatible with the empirical basis (Hull 1965; Simberloff 1980; Sober 1980). The transition from essentialism to population thinking has been described by Ernst Mayr (1988, 1996; but see Levit and Meister 2006; Winsor 2003). This transition followed directly from the Darwinian revolution (Darwin 1859): it is organisms with unique trait combinations that make up populations, that constitute biodiversity, and that are the basis of evolutionary change. The earlier paradigm, which viewed organisms as blueprints of unchangeable essences, was incompatible with these observations.

Equally important to modern biology is tree thinking. Each and every species occupies one specific place in the tree of life. Consequently all species have shared certain parts of their history with all other living and extinct species. The degree to which this history has been shared, allows us to predict the extent and way in which species differ from and resemble each other. A description of biodiversity is impossible or at least incomplete without taking this knowledge into account. It is necessary both for 
the idiographic activity of reconstructing evolutionary relationships between species, and for the nomothetic activity of testing hypotheses about biological laws of nature (Ghiselin 1997; Hull 1999). Phylogenetic reconstruction (Felsenstein 2004) and the comparative method (Martins and Hansen 1996) are thus entirely unthinkable without tree thinking.

Tree thinking became widely accepted somewhat later than population thinking, as it can be said to have originated with phylogenetic systematics (Hennig 1950). However, this does not mean that tree thinking has superseded population thinking (O'Hara 1997). Both perspectives are compatible, and both are necessary in biology today. As Robert O'Hara (1997) has shown, what has been replaced by tree thinking, are the earlier paradigms of group thinking and developmental thinking in evolutionary biology. Group thinking had equated systematics with classification, i.e. it perceived taxonomic groups as units that could be defined rather than entities that had to be discovered. Group thinking thus represented essentialism in systematics, because it failed to understand that taxa are evolving entities and thus, ontologically speaking, individuals (Ghiselin 1974, 1997; Hull 1976). Developmental thinking, on the other hand, had assumed that organic evolution was a teleological process (Ghiselin 2002; Hull 1974; Mayr 1988). It was thus based upon the ancient idea that change in nature has an ultimate goal. This is incompatible with the irregular and divergent nature of evolution.

One might presume that the replacement of group and developmental thinking by tree thinking is of merely historical interest - a subject to be dealt with by historians of science, just as the replacement of essentialism by population thinking. To the contrary, I here argue that the transition of both group thinking and developmental thinking to tree thinking is still happening, and that it deserves more attention by those who teach phylogenetics and who communicate phylogenies. The transition is still happening in the sense that students of biology have to accomplish it in the course of their "academic ontogenies": tree thinking is an ability that has to be acquired and cannot be taken for granted by teachers. Sadly, many text books indirectly and implicitly promote developmental thinking. This further aggravates the problem. Given the importance (even necessity) of tree thinking in order to fully appreciate the meaning of evolutionary results, this problem deserves attention.

\section{Materials and methods}

I devised a short questionnaire which was handed out during the first lesson in several classes of a university

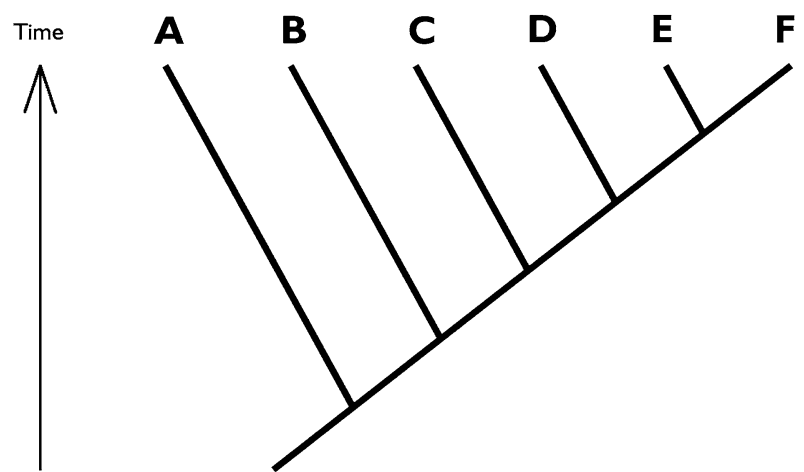

Fig. 1 Example phylogeny, where letters symbolise species. Not a single student $(n=31)$ was able to give the correct answer to the question "which species is/are most closely related to species B"

course in systematics and evolution (at Universitetet $\mathrm{i}$ Troms $\varnothing$, Norway). The course was intended for students who had studied biology for several terms, but this was not a formal requirement. The students who followed normal progression had been taught evolutionary principles and processes in earlier courses. The same questionnaire was used in a similar course at a regional university college (Høgskolen i Bodø, Norway). The students were asked to answer the questions, using the time they needed, and were assured anonymity. They did not have access to any books or notes.

The questions (and correct answers) were:

1. "Given the following evolutionary tree [reproduced in Fig. 1], where letters symbolise species: which species is (are) most closely related to species B?" (The correct answer was "C, D, E and F".)

2. "How many classes of vertebrates and angiosperms are there? Fill in the scientifically correct answer:..."(There is no scientifically correct answer to this question.)

3. "What are the differences between species and genera, or between orders and classes? Give one or more keywords that describe these differences. (a) Differences between species and genera:...(b) Differences

\footnotetext{
${ }^{1}$ Question (1) might require some linguistic explanations. The original question was "Gitt det følgende stamtreet der bokstaver symboliserer arter, hvilke(n) art(er) er i nærmest slekt med art B?" In Norwegian, "which species" has different endings in the singular and plural (while the verb does not, "er" = "is/are"). It was important not to imply in the question that the correct answer consisted of either one species or several species. Therefore, "hvilke(n) art(er)" is a combination of singular ("hvilken art") and plural ("hvilke arter"). Furthermore, "most closely related" is a quite imperfect translation of "i nærmest slekt". The Norwegian phrase implies a kinship or genealogical relation (comparable to the German "verwandt"). The English "related" is wider and also incorporates abstract relationships such as whole-part, group-element or simply similarities of any kind. The Norwegian word does not normally have these figurative connotations.
} 
between orders and classes:..."(The correct answer was that species differ from genera [and orders and classes], for instance by being populations within which gene flow can occur. The difference between orders and classes is merely one of definition, none of nature.)

4. "What does the 'tree of life' look like? Please draw the evolutionary tree which describes the relationships between groups of organisms. Include as many groups as you are able to recall".

\section{Results}

Twenty one university students returned questionnaires that were at least partly answered. On average they had previously taken biology courses for 1.6 years of full time study load (median 1.5 , range $0.3-4.0$ years). Four were graduate students, the remainder were undergraduates. A further ten students of the regional university college returned the questionnaire.

Not a single correct answer was given to question 1 . In most cases, species A (cf. Fig. 1) was the whole answer or part of the answer (17 of 20 university students, and 8 of 9 college students).

Of 20 answers to question 2, 18 consisted of numbers. One student entered strokes, and 1 left the answers blank.

In response to question 3, 5 of 18 respondents answered that species were fundamentally different from genera, while there was no such difference for orders and classes. The remainder answered that there was no important differences at all $(n=8)$ or that there were important differences between both species and genera, and between orders and classes $(n=5)$.

As an answer to question 4, 20 university students produced a drawing, however, 7 of them did not enter any names, and 1 entered one name only. The remainder provided between 4 and 23 taxon names. See Fig. 2 for an example.

Seven of 13 students depicted 1 to 9 extant taxa as stem groups in their drawings. A total of $14 \%$ of all names provided were drawn as stem taxa. 11 of 13 students drew 1 to 11 branches which they named with paraphyletic groups. A total of $31 \%$ of all names provided referred to paraphyla.

As regards the placement of our own species, or the taxon containing Homo sapiens, the placement of our taxon seemed arbitrary in four drawings, and in two cases no names provided referred to taxa that contained our species. Our taxon was placed at top of the drawing in five cases, and at the outermost position in two cases. This means that 7 of 13 respondents gave a special position to our taxon. Counting the number of nodes at which the path to H. sapiens leads to

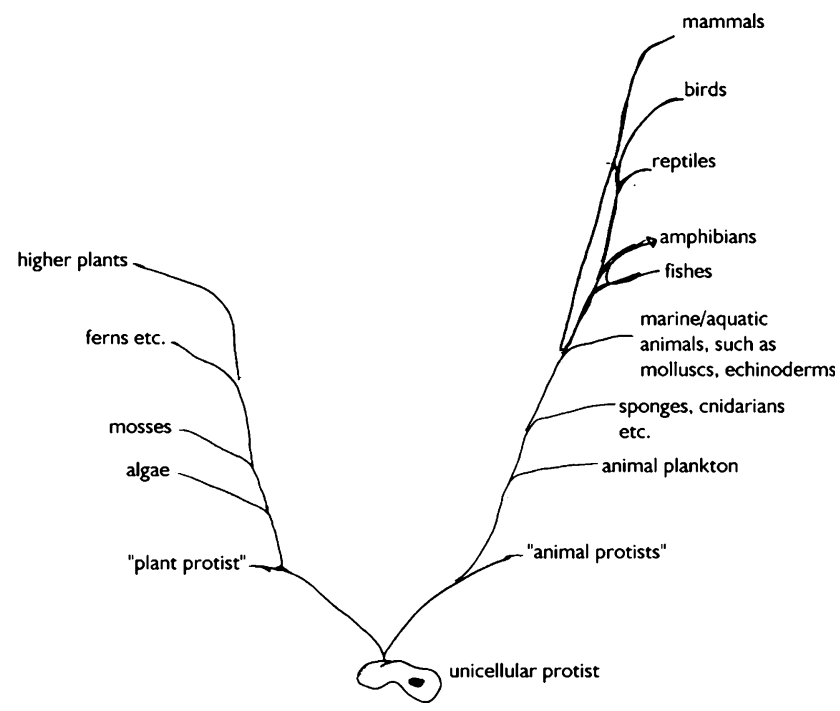

Fig. 2 Phylogenetic tree drawn by a university student. The question posed was "What does the 'tree of life' look like? Please draw the evolutionary tree which describes the relationships between groups of organisms. Include as many groups as you remember". Note the prominent position of mammals and the unresolved "side branches". Taxon names provided by the student were translated verbatim into English, the drawing itself is unchanged

the uttermost or uppermost position, a continuous "human utterness score" can be calculated (Sandvik 2008). Combined for the eleven drawings to which it was applicable, the average score was 0.90 (43 of 48 nodes), which is highly significantly biased in favour of man $\left(P<10^{-8}\right)$.

The resolution of the tree also favoured our species. I calculated scores of the relative attention the tree drawings devoted to three species, viz. H. sapiens (Mammalia), Vanessa atalanta (Lepidoptera) and Veronica fruticans (Lamiales), in the following manner: a score of 1 was assigned if the species was named, of 2 if at least the "order" was named, of 3 if at least the "class" was named, of 4 if at least the "phylum" was named, of 5 if a higher taxon was named, and of 6 if no named branch contained the species. The average attention score was $3.6 \pm 1.5$ (SD) for man, $4.8 \pm 1.2$ for the butterfly, and $4.6 \pm 1.3$ for the flower. A one-tailed Wilcoxon two-sample tests showed that man received more attention than the other two species ( $W=155.5, P<10^{-5}$ ). If using the "human attention score" defined elsewhere (Sandvik 2008), a continuous measure that expresses the degree to which tree resolution favours our own species, the average for the 13 tree drawings was 0.60 , which is highly significantly biased in favour of man $\left(P<10^{-4}\right)$.

\section{Discussion}

O'Hara (1997:327) remarked that "beginning students in biology should be taught how to read trees [...] just as 
beginning students in geography need to be taught how to read maps". My findings drastically support this opinion. None of the undergraduate or graduate students in my (admittedly small) sample was able to correctly interpret a simple cladogram (Fig. 1). The cladogram was certainly not the first evolutionary tree that the students had met, since most had studied biology for several terms, including introductory courses in evolutionary biology.

It does not require many sentences to explain how a cladogram should be read. The concept of evolutionary relatedness is not hard to grasp once it is explained. If it is not, however, erroneous conceptions seem to be able to survive for several years during prospective biologists' educational careers. At the end of my course all university students were able to give correct interpretations of cladograms. Matters differed for the students of the regional university college. These students were asked which of the small cladograms in Fig. 3b-i were compatible with the large cladogram (Fig. 3a). This latter question was posed after the meaning of cladograms had been explained and after a considerable amount of time had been spent practicing the reading of cladograms. Still, only one answer out of fourteen correctly identified all of the three compatible cladograms. The remainder failed to identify at least one compatible cladogram and/or indicated at least one incompatible tree as compatible. This sobering result might be related to the fact that many of the college students simply needed some biology courses in order to study, e.g. fishery. They might thus not have been genuinely interested in biology per se, so that these findings would need to be replicated with university students. Still, it is independent evidence that reading cladograms is very much an acquired ability rather than one that can be presupposed.

In their answers, the students proved to pay more attention to how the taxon names at the tree tips were ordered along the left-right axis, than to the topology of the cladogram. Given that the information of cladograms is conveyed in the branching order of taxa, while the leftright ordering is arbitrary, this wrong focus necessarily leads to wrong conclusions.

The main problem is presumably that students simply have not been taught how to read cladograms. Teachers may often assume that cladograms are self-explicatory graphic devices to illustrate phylogenetic relationships, when in fact their interpretation is not trivial. As Halstead (1978:760) put it: "Cladograms are difficult enough for experts in the field to comprehend fully". Ironically, what he was advocating as the obvious alternative was phylograms-which were meant to not only express phylogenetic relationships, but, in addition, phenotypic similarity, distribution through geologic time and species number. As such, phylograms are not only harder to interpret for untrained readers than cladograms. They may also convey incorrect information on any one of the aspects because they represent a two-dimensional compromise of several multidimensional measures.

Regrettably, the presentation of systematics in text books has been lagging behind the cutting edge of systematic research by several decades. It is thus only quite recently that most biological text books have replaced phylograms with cladograms. A less appreciated fact is that even displaying cladograms does not guarantee that the information provided is unbiased, as many cladograms are drawn in an anthropocentric fashion (Sandvik 2008). It might thus well be that one source of confusion for students is the ambiguity of evolutionary tree drawings in text books. Drawings of evolutionary trees cannot be clearer than their authors' thoughts about evolutionary processes. And the latter have long been rather muddled, as can be exemplified by the occurrence of "stem groups" in many text book trees (e.g. Villee et al. 1984: Fig. 19.6; Willmer 1990: Fig. 14.2, which has even been reprinted by a number of other text books). However, stem groups have never existed in nature. A taxon above the species level cannot possibly give rise to other taxa-nor to anything else (Ghiselin 1997). One might say, therefore, that stem groups are just another way of expressing (or, worse still, trying to hide) ignorance. That some taxonomists have chosen to even give scientific names to their ignorance (e.g. "Procoelomata"; Bergström 1989), does not really make the matter more transparent for biologists under education. No wonder, then, that stem groups occurred in $54 \%$ of the student drawings.

One problem is thus that many tree drawings which students meet during their studies are biased and thereby distort the evolutionary understanding of their readers. Another is that this distorted understanding even impinges on the interpretation of correctly drawn phylogenetic trees. In other words, both problems re-enforce each other. I have demonstrated elsewhere that even cladograms in phylogenetic text books are biased in an anthropocentric way (Sandvik 2008). In terms of ordering of taxa and differential resolution of branches, otherwise correct cladograms may distort the understanding of evolution. These findings make the evidence presented here even more alarming: If taxa are ordered in an anthropocentric manner in most cladograms, and if students rely more on ordering than topology, this affects the interpretation of relationships. The taxon containing our own species is most often placed in the rightmost position in cladograms (Sandvik 2008). This can be illustrated with Fig. 4, which displays the phylogeny of Osteognathostomata in an anthropocentric manner. The topology of the cladogram is the same as in Fig. 1. Accordingly, many untrained student of biology can be expected to conclude that coelacanths are more closely related to ray-finned fishes than to mammals. 
Fig. 3 Nine phylogenetic trees over Mollusca with different topologies. a was used as a reference phylogeny. Students were asked which of the eight small trees were compatible with the reference tree. The eight topologies $\mathbf{b}-\mathbf{i}$ differ from $\mathbf{a}$ in either the phylogenetic relationships displayed (making them incompatible with a), resolution of some of the branches, placement of taxa along the left-right axis, or a combination of those (only $\mathbf{c}, \mathbf{g}$ and $\mathbf{h}$ are compatible with $\mathbf{a}$. In the tree distributed to students, all names were given as unabbreviated Norwegian vernacular names)

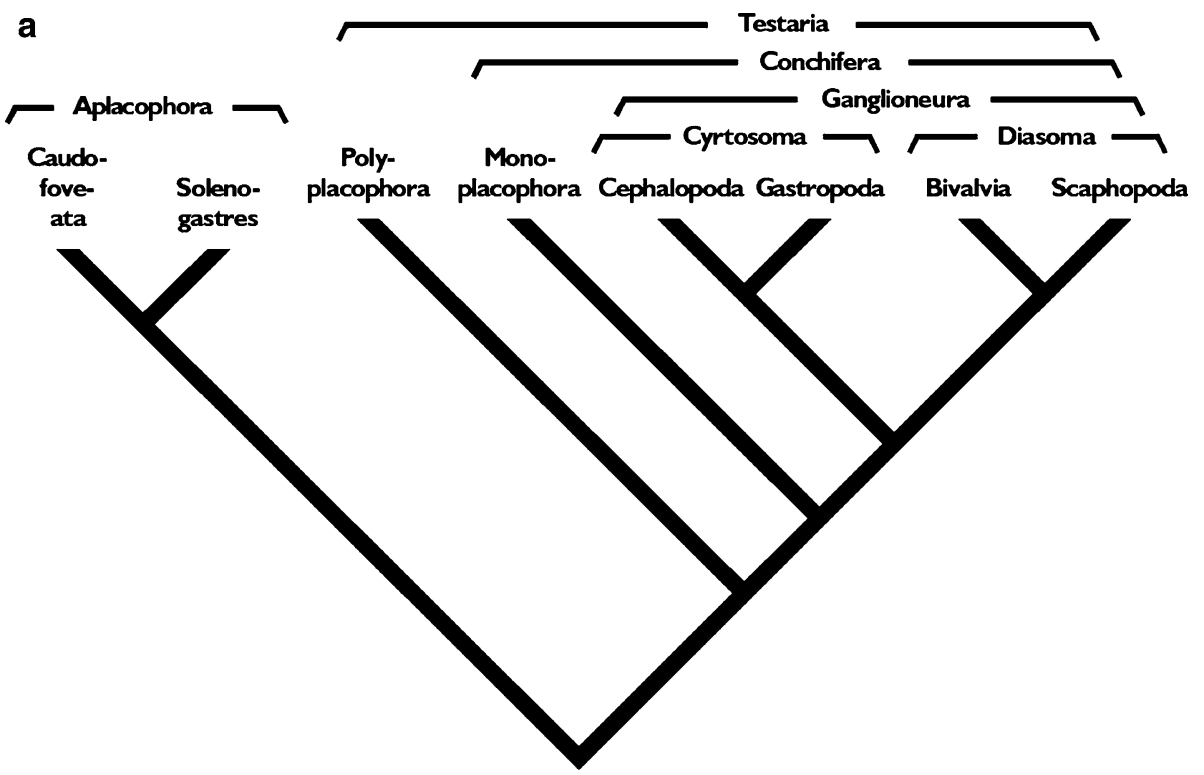

b

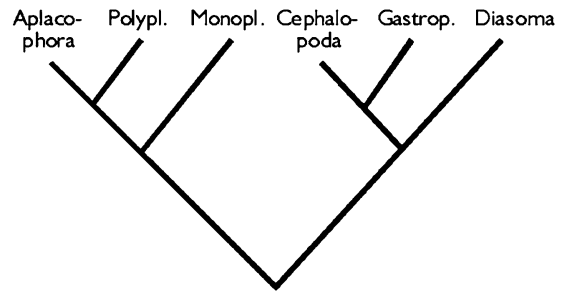

d

C

Aplaco- Polypl. Gastrop. Cephalo- Diasoma Monopl. phora

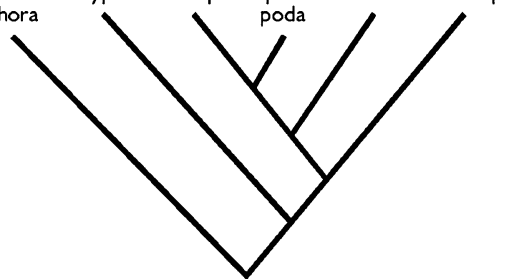

Aplaco- Monopl. Gastrop. Cephalo- Diasoma Polypl.

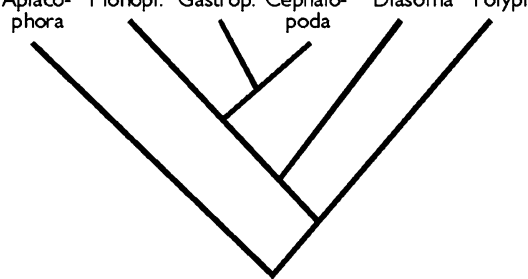

e

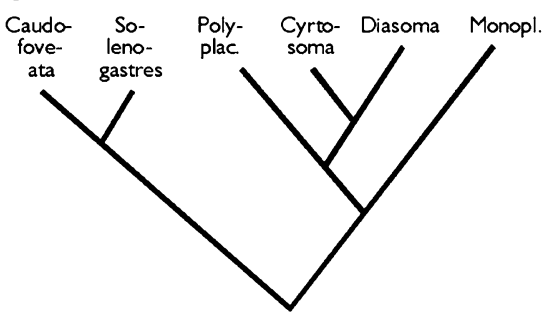

f

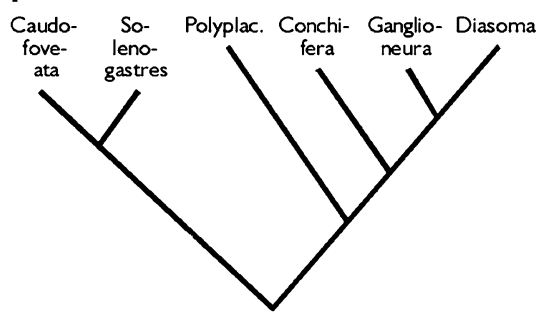

h

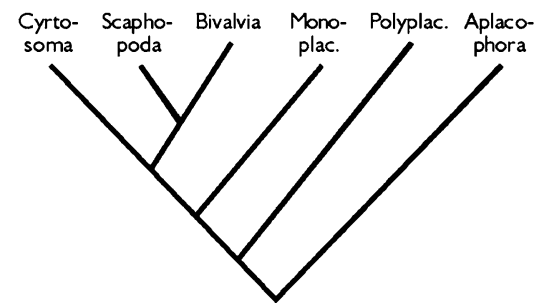

g Monopl. Diasoma Cyrto- Polyplac. Caudo- So-

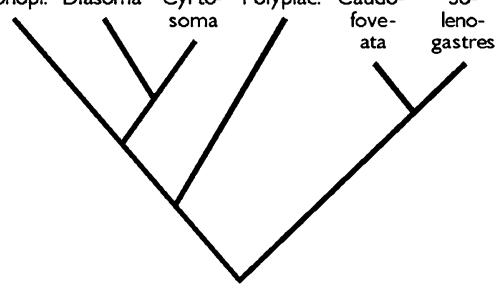

i Monopl. Gastrop. Bivalvia Scapho Polypl. Aplaco-

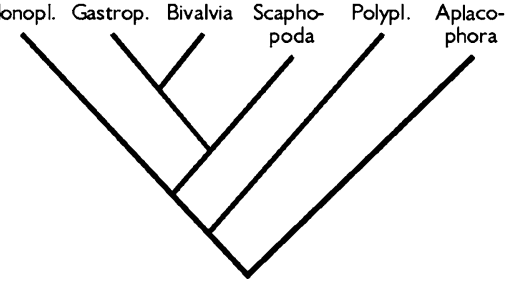




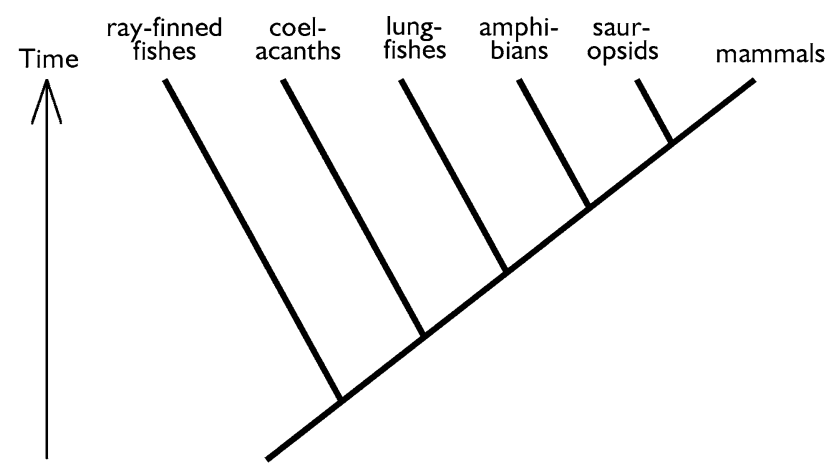

Fig. 4 Cladogram depicting the phylogeny of bony vertebrates (Osteognathostomata). The cladogram is anthropocentric in that both the resolution of its branches and the ordering of taxon names are biased in favour of mammals. Note that the tree topology is identical to Fig. 1. See text for further details

The students' inability to answer question 1 (Fig. 1) might be argued to have other reasons. An obvious alternative explanation would be that the error was caused by a simple misunderstanding of the word "relationship", and that it is sufficient to tell students that relationship, as used in evolutionary biology, is a technical term meaning "the relative recency of common ancestry" (Mayr 1974). However, the question to the students was posed in Norwegian, were the word "slektskap" only has the latter meaning. In other words, while knowledge of the precise meaning of "relationship" is necessary (especially in English), it is not sufficient for students to understand cladograms.

In passing I would like to mention a speculation on the reason why phylogenetic systematics and cladistic methodology was rather quickly accepted in Germany (Ax 1977; Remane 1956; Schlee 1969), but provoked intense debates in English-language journals (verifiable with almost any issue of Systematic Zoology from the 1970s). I suspect that part of the problem was semantic. The German word for "relationship" is "Verwandtschaft", but while the English word has all kind of abstract and symbolic connotations, including overall similarity, the German term is reserved for true, genealogical bonds (as is the Norwegian "slekt", see footnote ${ }^{1}$ ). The statement that for instance the lungfish is more closely "verwandt" to the cow than to the salmon is quite uncontroversial in German. On the other hand, the statement that the lungfish is more closely related to the cow than to the salmon, was able to create a heated discussion-which was only peripherally concerned with the actual phylogeny of the groups concerned (Gardiner et al. 1979; Halstead 1978; Halstead et al. 1979).

A final observation concerns the importance attributed to Linnean categories (i.e. labels such as "family", "order", etc.) by students. It is well-established that Linnean categories above the species level do not carry information, that they are not comparable across taxa, and that it is entirely arbitrary to which taxa they are assigned in the first place (de Queiroz and Gauthier 1992; Donoghue 2001; Ereshefsky 1994, 2001, 2002). Many taxonomists have abandoned categories altogether, simply referring to taxa by their names. However, few students are aware of the arbitrariness of Linnean categories. In many undergraduate text books, the enumeration (!) of animal "phyla" or insect "orders" seems to be more important than the discussion of interrelationships between the taxa concerned (e.g. Barnes et al. 1998). This leaves students with the impression that categories must express something. Unless told otherwise, they tend to make up their own explanations. As my results indicate, only a tiny proportion of students seems to question the existence and reality of Linnean categories. Of course, blank answers to question 2 do not necessarily indicate the deliberate rejection of categories - the two students may also have wished to give a number, but were unable to "recall the correct one". On the other hand, question 2 was clearly a leading (not to say, loaded) question, which may have biased the respondents into thinking that a number was the only acceptable answer. Still, findings from question 3 show that at least $27 \%$ of the students perceive the distinction between "orders" and "classes" to be a reflection of real differences between natural levels of organisation.

The findings presented here re-enforce earlier reports that reading cladograms is an ability that has to be practiced (O'Hara 1992, 1997). Even though the transition from developmental thinking to tree thinking is more or less completed in the science of systematics at the collective level, it has to be accomplished anew by every generation of biology students on the individual level. This must not be forgotten when teaching phylogenetics or writing or illustrating text books. Other topics that need to be addressed explicitly are the artificiality of Linnean categories, the non-existence of stem taxa, and the arbitrariness of paraphyla. It does not seem to be sufficient to "get the facts right" in teaching and text books. Students tend to fall back to group and developmental thinking unless explicitly told otherwise.

Open Access This article is distributed under the terms of the Creative Commons Attribution Noncommercial License which permits any noncommercial use, distribution, and reproduction in any medium, provided the original author(s) and source are credited.

\section{References}

Ax P (1977) Willi Hennig. 20.4.1913 bis 5.11.1976 [Nachruf]. Verh Dtsch Zool Ges 70:346-347

Barnes RSK, Hemsley A, Margulis L, Chapman MJ, Sagan D, Pirozynski KA (1998) The diversity of living organisms. Blackwell, Oxford 
Bergström J (1989) The origin of animal phyla and the new phylum Procoelomata. Lethaia 22:259-269

Darwin C (1859) On the origin of species by means of natural selection, or the preservation of favoured races in the struggle for life. Murray, London

de Queiroz K, Gauthier J (1992) Phylogenetic taxonomy. Annu Rev Ecol Syst 23:449-480

Donoghue MJ (2001) A wish list for Systematic Biology. Syst Biol 50:755-757

Ereshefsky M (1994) Some problems with the Linnean hierarchy. Philos Sci 61:186-205

Ereshefsky M (2001) The poverty of the Linnean hierarchy: a philosophical study of biological taxonomy. Cambridge University Press, Cambridge

Ereshefsky M (2002) Linnean ranks: vestiges of a bygone era. Philos Sci 69(Suppl):S305-S315

Felsenstein J (2004) Inferring phylogenies. Sinauer, Sunderland

Gardiner BG, Janvier P, Patterson C, Forey PL, Greenwood PH, Miles RS, Jefferies RPS (1979) The salmon, the lungfish and the cow: a reply. Nature $277: 175-176$

Ghiselin MT (1974) A radical solution to the species problem. Syst Zool 23:536-544

Ghiselin MT (1997) Metaphysics and the origin of species. State University of New York Press, Albany

Ghiselin MT (2002) Teleology: grounds for avoiding both the word and the thing. Hist Philos Life Sci 24:487-491

Halstead LB (1978) The cladistic revolution-can it make the grade? Nature 276:759-760

Halstead LB, White EI, MacIntyre GT (1979) The salmon, the lungfish and the cow: L. B. Halstead and colleagues reply. Nature 277:176

Hennig W (1950) Grundzüge einer Theorie der Phylogenetischen Systematik. Deutscher Zentralverlag, Berlin

Hull DL (1965) The effect of essentialism on taxonomy-two thousand years of stasis. Br J Philos Sci 15:314-326; 16:311-318

Hull DL (1974) Philosophy of biological science. Prentice-Hall, Englewood Cliffs
Hull DL (1976) Are species really individuals? Syst Zool 25:174-191

Hull DL (1999) The use and abuse of Sir Karl Popper. Biol Philos 14:481-504

Levit GS, Meister K (2006) The history of essentialism vs. Ernst Mayrs "essentialism story": a case study of German idealistic morphology. Theory Biosci 124:281-307

Martins EP, Hansen TF (1996) A microevolutionary link between phylogenies and comparative data. In: Harvey PH, Leigh Brown AJ, Maynard Smith J, Nee S (eds) New uses for new phylogenies. Oxford University Press, Oxford, pp 273-288

Mayr E (1974) Cladistic analysis or cladistic classification? Z Zool Syst Evolforsch 12:94-128

Mayr E (1988) Toward a new philosophy of biology: observations of an evolutionist. Harvard University Press, Cambridge \& London

Mayr E (1996) The autonomy of biology: the position of biology among the sciences. Q Rev Biol 71:97-106

O'Hara RJ (1992) Telling the tree: narrative representation and the study of evolutionary history. Biol Philos 7:135-160

O'Hara RJ (1997) Population thinking and tree thinking in systematics. Zool Scr 26:323-329

Remane A (1956) Die Grundlagen des natürlichen Systems, der vergleichenden Anatomie und der Phylogenetik, 2nd ed. Akademische Verlagsgesellschaft, Leipzig

Sandvik H (2008) Anthropocentricisms in cladograms. Biol Philos 23: in press (doi:10.1007/s10539-007-9102-x)

Schlee D (1969) Hennig's principle of phylogenetic systematics, an "intuitive, statistico-phenetic taxonomy"? Syst Zool 18:127-134

Simberloff D (1980) A succession of paradigms in ecology: essentialism to materialism to probabilism. Synthese 43:3-39

Sober E (1980) Evolution, population thinking, and essentialism. Philos Sci 47:350-383

Villee CA, Walker WF Jr, Barnes RD (1984) General zoology, 6th edn. Saunders, Philadelphia

Willmer P (1990) Invertebrate relationships: patterns in animal evolution. Cambridge University Press, Cambridge

Winsor MP (2003) Non-essentialist methods in pre-Darwinian taxonomy. Biol Philos 18:387-400 